Conclusions: Rheumatology nurse phone follow-up program provided a timely and convenient platform to increase patient understanding of disease and treatment, improve their self-efficacy and enhance safety and concordance with DMARDs treatment.

Disclosure of Interest: None declared

DOI: 10.1136/annrheumdis-2017-eular.4421

\section{THU0769-HPR SCOPE FOR BIOLOGIC PRESCRIBING COST SAVING INITIATIVES WITHIN THE RHEUMATOLOGY DEPARTMENT}

${ }_{\text {R. Heaton }}{ }^{1}$, J. Nasralla ${ }^{1}$, A. Ismail ${ }^{1}$, A. Brooks ${ }^{2}$, L. Mercer ${ }^{1}$, C. Filer ${ }^{1}$. ${ }^{1}$ Rheumatology; ${ }^{2}$ Pharmacy, Stepping Hill Hospital, Stockport, United Kingdom

Background: The rheumatology department at Stepping Hill Hospital prescribes biologic treatment for 400 inflammatory arthritis patients via external Homecare services. Significant resultant drug waste in the event of drug discontinuation is anticipated. ${ }^{1}$ The initiation of a pro-active telephone call at three months, to capture and act upon primary inefficacy and non-tolerance has been considered as a potential alternative method for waste reduction.

Objectives: Establish the baseline level of biologic drug waste (via Homecare) following cessation of biologic treatment. Review whether a proactive phone call (and subsequent limitation of supply if appropriate) prior to the three month review at the start of biologic therapy can help reduce biologic waste. Establish whether there is scope to implement other initiatives to reduce waste in the department. Methods: Patients who had stopped or switched biologic treatments delivered through Homecare providers were identified using the trust's biologic database and clinic records. Information on biologic delivery quantities and schedule were provided by Homecare companies. Data was analysed used Microsoft Excel ${ }^{\circledR}$; number (and cost in accordance with pharmacy tariffs) of doses "wasted" was calculated by referring the date of treatment cessation with the date and quantity of last biologics deliveries and patient stock levels as reported by the homecare company. Doses obtained free of charge were excluded. Baseline data was captured over a six month period. Four costs were calculated; (1) Total waste. (2) Wasted supply exceeding two months to assess whether an increase in delivery frequency to two monthly could reduce waste. (3) Waste from unopened deliveries to establish whether waste could be reduced by improved patient education around refusing deliveries in the event of treatment failure or intolerance. (4) Waste from the second biologic prescription issued as a result of stopping biologic at the three month review to assess viability of the proactive phone. A proactive patient phone call was then initiated and waste data captured for a three month period following this intervention.

Results: 27 patients stopped treatment during the 6 months baseline data collection. 23 patients had drug waste totalling $£ 32,140.80$. The total value of wasted stock exceeding two months supply was $£ 5,414$.36. Three patients accepted deliveries for further supply and stopped treatment before opening final deliveries, creating a waste total of $£ 5,509.09$. Four patients stopped treatment at their three month review, $£ 4,572.22$ of additional biologic was supplied and then wasted as a result. Following the pro-active phone call intervention, 21 patients were contacted before their second supply was due and supply subsequently limited for 8 patients, four of whom stopped treatment at their next consultant review. Limiting supply in the four patients saved $£ 6,682$.

Conclusions: Initiating a proactive phone call at three months following biologic initiation can reduce drug waste. Other initiatives such as patient education to refuse deliveries and increasing delivery frequency also appear viable waste reduction initiatives.

\section{References:}

[1] Whiteman J, McVeigh O, Watters M. Hospital Pharmacy and the Pharmaceutical Industry Collaborate to Reduce Waste of Biologic Medicine. Rheumatology. 2016 Apr 1;55.

Disclosure of Interest: None declared

DOI: 10.1136/annrheumdis-2017-eular.6333

\section{THU0770-HPR COST SAVINGS BY FAVOURING INFLIXIMAB BIOSIMILARS IN THE EASTERN REGION OF AUSTRIA}

B. Reichardt ${ }^{1}$, G. Reiter ${ }^{1}$, T. Stamm ${ }^{2}$, V. Nell-Duxneuner ${ }^{3}$. ${ }^{1}$ Behandlungsökonomie, BGKK, Eisenstadt; ${ }^{2}$ Section for Outcomes Research, Center for Medical Statistics, Informatics, and Intelligent Systems, Vienna; ${ }^{3} 3$ Klinikum Peterhof and Ludwig Boltzmann Department for Epidemiology of rheumatic diseases, Nögkk, Baden, Austria

Objectives: Since April 2015, the availability of Infliximab biosimilars offered a new potential for cost savings in limited financial resources of the healthcare system. In Austria, there is currently no open tendering for drugs dispensed at charge of sickness funds and biosimilars take a long time to gain an appreciable market share overall. A contract made between the public hospital operator and the regionale sickness fund of the Eastern Austrian county Burgenland (BGKK) offered a new opportunity regarding the interface problems due to the dually financed (inpatient and outpatient care is separately financed in Austria) health system. Only outpatient care is covered by regional sickness funds.

Methods: With reference to the NOR-SWITCH study (1), confirming the interchangeability of the branded Infiximab and infliximab biosimilar, and the large price advantage of the latter, the BGKK agreed as an exception in the Austrian health system on direct reimbursement of infliximab to the public hospital operator (inpatient care).

The cost savings were calculated based on the monthly invoices of the hospitals. Instead of $€ 477.19$ for $100 \mathrm{mg}$ of branded infliximab, the price for biosimilar infliximab does not exceed $€ 300$.-. The 23 patients on biosimilar were infused with $9,400 \mathrm{mg}$ infliximab overall.

Results: After signing the agreement in December 2016, 23 consecutive patients, representing $82 \%$ of all patients on infliximab in Eastern Austrian county Burgenland, switched to or were incident users of an infliximab biosimilar, the $18 \%$ have not yet switched due to remaining stocks of branded infliximab or were adolescents where switching is not forced because of lacking data. According to the individual dosing and a price benefit of about $37 \%$, monthly cost savings of about $€ 16,650.00$ could be generated.

Conclusions: Despite availability of cost-effective infliximab biosimilars in Austria, the drugs did not gain significant market share, in contrast to the Scandinavian healthcare systems, $<4 \%$ vs. $>90 \%$ in the first half year of 2016 . Further research is needed including clinical data to strengthen the results of this pilot study.

References:

[1] Jørgensen, K. et al. Biosimilar infliximab is not inferior to originator infliximab: Results from the 52-week randomized NOR-SWITCH trial. United European Gastroenterology Week 2016; LB15.

Disclosure of Interest: None declared

DOI: 10.1136/annrheumdis-2017-eular.6202

\section{THU0771-HPR INCORPORATING SENIOR PHARMACIST INPUT IN TERIPARATIDE PATHWAY ENSURES ADHERENCE TO PRESCRIBING GUIDANCE - AUDIT/QUALITY IMPROVEMENT RESULTS FROM A DISTRICT RHEUMATOLOGY UNIT}

W. Gan, L. Bromilow, S. Vasireddy. Bolton NHS Foundation Trust, Bolton, UK

Background: Teriparatide is licensed for upto two years to treat severe osteoporosis. It is the most expensive osteoporosis treatment available (around £ 3500 per year). Hence a locally adapted national NICE guidance is used for prescribing in our department, but the previous level adherence was uncertain. In 2011, a directory of services was agreed for our metabolic bone clinic. At the time a Rheumatology senior pharmacist review with the prescribing senior clinician was agreed on our teriparatide treatment pathway, including pre-treatment DXA, and a specified bone profile screen before treatment and for repeat prescribing at specified intervals. The agreement also incorporated access for our patients to senior pharmacist advice if needed via the department's secreterial team.

Objectives: Our objective was to assess the impact of the senior pharmacist input on our adherence to the agreed guidelines in our Teriparatide pathway, including assessing treatment completion and response.

Methods: Patients with osteoporosis who were started on Teriparatide between 2011-2015 were identified from pharmacy prescribing spreadsheets. A retrospective review of case notes of all patients were carried out. Data including age, gender, prior agents tried, pre-treatment bone profile, pre and post treatment DXA, and treatment completion were collected on a Microsoft Excel 2010 spreadsheet for processing and descriptive statistics.

Results: 33 patients who were started on teriparatide treatment between 20112015 were identified (29 female and 4 male). Mean age was 76.2 (range 63-92). All had pre-treatment DXA, and $32(97 \%)$ were compliant with recommendations for initiation of teriparatide treatment with respect to DXA (one patient borderline). All 33 patients had a pre-treatment bone profile within acceptable limits before start of treatment (adjusted Calcium, Serum Parathyroid Hormone, Vitamin D level, e-gfr). $28(84.8 \%)$ patients tried one agent before initiation of Teriparatide treatment and $5(15.2 \%)$ patients tried 2 agents. $24(72.7 \%)$ patients completed the full course of recommended treatment. 11 out of 24 patients who completed Teriparatide treatment have had post-treatment DXA. 3 out of 24 patients who completed Teriparatide treatment had a fragility fracture after treatment.

Conclusions: This audit confirms the benefit of incorporating Rheumatology senior pharmacist review in the pathway from the excellent compliance with guidelines in initiating and managing Teriparatide noted in the results. This is likely to have also contributed to the high completion rate of the treatment course. However, only 11 out of 24 had post treatment DXA, and this needs improvement by the next audit cycle, through input of senior clinicians who are in charge of requesting DXA. We would, therefore, recommend incorporating senior pharmacist input for review in teriparatide treatment pathways routinely.

Disclosure of Interest: None declared

DOI: 10.1136/annrheumdis-2017-eular.7031

\section{THU0772-HPR VARIATION IN RHEUMATOLOGY NURSING CARE IN THE NETHERLANDS: A SURVEY AMONG NURSES}

Y. Van Eijk-Hustings on behalf of Working Group Rheumatology Nursing Research. Clinical epidemiology and medical technology assessment/Patient \& Care, Maastricht University Medical Centre, Maastricht, Netherlands

Background: EULAR recommendations for the role of nurse aim at guaranteeing a certain standard of care for people with rheumatic musculoskeletal diseases 